DOI: 10.20472/IAC.2018.040.038

\title{
YEONHO LEE
}

Chungbuk National University (Department of Economics), Korea, Republic of

\section{KWANGSUK HAN}

Pusan National University (Department of International Trade), Korea, Republic of

\section{OCA AND EAST ASIAN MONETARY UNION: ANALYZING ASYMMETRY OF SHOCKS}

\begin{abstract}
:
There have been studies applying OCA criteria to East Asia and they have focused largely on evaluating the economic conditions for regional monetary integration in East Asia. Many of their studies find that at least some of the Asian countries meet major OCA criteria. This paper investigates the feasibility and desirability of a common currency arrangement in East Asia applying a structural VARs methodology to asymmetric shocks. We examine the issues of asymmetric responses to external shocks which is one of the most frequently used criteria for evaluating the costs and benefits of joining a common currency versus having an independent currency.

The results suggest that a sub-group of East Asian countries are plausible candidates for adopting a single currency. Regarding asymmetry of supply shocks, we find that eight East Asian economies (Hong Kong, Indonesia, Japan, Korea, Malaysia, Singapore, Taiwan, and Thailand) are possible candidates for a currency union (EA 8), and EA 5 for demand shocks. Supply disturbances are highly and significantly correlated among these countries and correlations of real GDP growth rates corroborate the analysis of supply disturbances.
\end{abstract}

\section{Keywords:}

Optimum Currency Area (OCA), Monetary Union, East Asia, Structural VARs

JEL Classification: F41, F33, F36 